\title{
PERBEDAAN HASIL BELAJAR SISWA YANG MENGGUNAKAN MULTIMEDIA INTERAKTIF DENGAN BUKU TEKS DALAM PEMBELAJARAN BIOLOGI DI SMA
}

\author{
Asrizal Wahdan Wilsa \\ Sekolah Tinggi Keguruan dan Ilmu Pendidikan Nahdlatul Ulama Indramayu \\ Email: Asrizalwahdanwilsa@stkipnu.ac.id
}

Doi: https://doi.org/10.31943/mangiferaedu.v4i1.42

Received: 26 Juli $2019 \quad$ Accepted: 20 Agustus 2019 Published: 23 Agustus 2019

Citasi: Wilsa, A.W. (2019). Perbedaan Hasil Belajar Siswa yang Menggunakan Multimedia Interaktif dengan Buku Teks dalam Pembelajaran Biologi di SMA. Jurnal Mangifera Edu. 4(1): 62-70.

\begin{abstract}
Learning is a process that requires resources as a support in the success of learning. As an educator, teachers must be careful in choosing the learning resources needed by students, so that the learning process can be achieved according to the purpose of learning. But in fact, the learning that teachers do in schools is still not utilizing the media as an appropriate learning resource for students, especially in the understanding of abstract biological concepts that require supporting media for student learning. This study aims to describe differences in student learning outcomes that use interactive multimedia with textbooks in biology learning at senior high school. The method used in this study is quasi-experimental, with Control Group Pretest - Posttest Design. Population in this research is class XI-MIPA I and XI-MIPA II. Class XI-MIPA I as experimental class and class XI-MIPA II as control class. The data were obtained by using a multiple choice test instrument of 30 questions. Based on the results of the pretest and posttest it was found that the average value of the experimental class was greater than the control class. Based on these findings, it can be concluded that there are differences in student learning outcomes that use interactive multimedia with textbooks in biology learning at senior high school.
\end{abstract}

Keywords: Interactive Multimedia, Text Book, Student Learning Outcomes.

\section{ABSTRAK}

Pembelajaran merupakan proses yang membutuhkan sumber (resource) sebagai penunjang dalam keberhasilan belajar. Sebagai seorang pendidik, guru harus cermat dalam memilih sumber belajar yang dibutuhkan oleh siswa, sehingga proses pembelajaran yang dilakukan dapat tercapai sesuai tujuan pembelajaran. Namun pada kenyataannya, pembelajaran yang dilakukan guru di sekolah masih belum memanfaatkan media sebagai sumber belajar yang tepat bagi siswa terutama dalam pemahaman konsep-konsep biologi yang bersifat abstrak yang membutuhkan media penunjang untuk pembelajaran. Penelitian ini bertujuan untuk mendeskripsikan perbedaan hasil belajar siswa yang menggunakan multimedia interaktif dengan buku teks dalam pembelajaran biologi di SMA. Metode yang digunakan dalam peneltian ini adalah quasi-eksperimental, dengan desain Control Group Pretest-Posttest Design. Populasi dalam penelitian ini adalah kelas XI-MIPA I dan XI-MIPA II. Kelas XI-MIPA I sebagai kelas eksperimen dan 
kelas XI-MIPA II sebagai kelas kontrol. Data diperoleh dengan menggunakan instrument tes pilihan ganda sebanyak 30 soal. Berdasarkan hasil pretest dan posttest diketahui nilai rata-rata kelas eksperimen lebih besar daripada kelas kontrol. Berdasarkan temuan tersebut dapat disimpulkan terdapat perbedaan hasil belajar siswa yang menggunakan multimedia interaktif dengan buku teks dalam pembelajaran biologi di SMA.

Kata Kunci: Multimedia Interaktif, Buku Teks, Hasil Belajar Siswa.

\section{PENDAHULUAN}

Pembelajaran merupakan proses yang membutuhkan sumber (resource) sebagai penunjang dalam keberhasilan belajar. Sumber yang dibutuhkan untuk menunjang proses pembelajaran sangat beragam dan harus sesuai dengan materi dan kondisi pembelajaran yang akan dilakukan oleh guru. Guru berperan penting dalam proses pembelajaran, sehingga guru dituntut cermat dalam memilih sumber belajar sesuai dengan kebutuhan. Guru juga dituntut untuk mampu mendesain, merancang, membuat, dan menggunakan berbagai jenis sumber belajar yang akan digunakan. Karena, suatu pembelajaran yang efektif akan terjadi jika bahan dan sumber belajar yang diperlukan tersedia. Sehingga apa yang disampaikan oleh guru dapat diterima dengan maksimal oleh siswa. Sementara itu, yang dimaksud dengan sumber belajar (learning resources) menurut Rohani dalam Musfiqon (2012: 129), adalah "segala macam sumber yang ada di luar diri siswa yang keberadaannya memudahkan terjadinya proses belajar". Jadi, sumber belajar tidak lain adalah segala macam sumber yang dapat digunakan untuk mendukung proses belajar. Dengan kata lain, sumber belajar merupakan hal yang sangat penting untuk menunjang hasil belajar siswa. Sebagian besar sekolah di Indonesia menggunakan buku teks sebagai sumber belajar wajib dalam pembelajaran.

Menggunakan media dalam proses belajar akan membantu meningkatkan hasil belajar siswa. Siswa akan lebih tertarik dan lebih memahami materi pelajaran jika sumber belajar dan media belajarnya mencukupi. Di era teknologi dan informasi ini, pemanfaatan kecanggihan teknologi untuk kepentingan pembelajaran bukan hal yang baru lagi. Salah satu pemanfaatan kecanggihan teknologi tersebut yaitu dengan pembelajaran berbasis multimedia.

Munir (2012: 110) mengatakan multimedia merupakan perpaduan antara berbagai media (format file) yang berupa teks, gambar (vector atau bitmap), grafik, sound, animasi, video, interaksi, dan lain-lain yang telah dikemas menjadi file digital (komputerisasi), digunakan untuk menyampaikan pesan kepada publik. Dengan demikian multimedia merupakan suatu media yang menyajikan informasi dalam bentuk file digital yang 
didalamnya terdapat teks, gambar, grafik, sound (suara), animasi, video, interaksi, dan lainlain. Dengan terdapatnya teks, gambar, grafik, sound (suara), animasi dan video multimedia mempunyai fungsi interaktif dalam pembelajaran. Fungsi interaktif tersebut karena multimedia melibatkan komunikasi dua arah atau lebih dari komponen-komponen komunikasi.

Komponen-komponen komunikasi yang terlibat dalam multimedia interaktif (berbasis komputer) adalah manusia (sebagai user/pengguna produk) dan komputer meliputi software, aplikasi, produk dalam format tertentu seperti flash (.swf), PDF (.pdf), PPT (.ppt), dan lainlain. Dengan demikian, produk berupa $\mathrm{CD} /$ software/aplikasi diharapkan dapat memiliki hubungan timbal balik antara software/aplikasi dengan penggunanya (user). Sementara itu, interaktifitas dalam multimedia meliputi: (1) pengguna (user) dilibatkan untuk berinteraksi dengan software/aplikasi; (2) aplikasi informasi interaktif bertujuan agar pengguna bisa mendapatkan hanya informasi yang diinginkannya saja.

Berdasarkan pengertian multimedia dan interaktif diatas, dapat disimpulkan bahwa multimedia interaktif adalah suatu tampilan multimedia yang dirancang oleh desainer agar tampilannya memenuhi fungsi menginformasikan pesan dan memiliki interaktifitas kepada penggunanya (user) (Munir, 2012: 110).

Pembelajaran dengan menggunakan multimedia dapat memadukan media-media lain dalam proses pembelajaran, sehingga proses pembelajaran akan berkembang dengan baik dan membantu pendidik menciptakan pola penyajian informasi yang interaktif.

Penelitian telah menunjukkan bahwa orang mengingat $20 \%$ apa yang mereka lihat, $40 \%$ dari apa yang mereka lihat dan dengar, namun sekitar $75 \%$ dari apa yang mereka lihat dan dengar dan lakukan secara bersamaan (Lindstrom dalam Munir, 2012: 111). Dari penelitian tersebut, orang dapat mengingat sekitar $75 \%$ dari apa yang mereka lihat dan dengar dan lakukan secara bersamaan. Oleh karena itu penggunaan multimedia interaktif dalam pembelajaran dapat meningkatkan hasil belajar siswa.

Munir (2012: 45) mengatakan bahwa setelah melakukan perbandingan, dikatakan bahwa peserta didik yang belajar dengan melihat gambar animasi ternyata lebih mudah mengerti materi yang disampaikan dibandingkan dengan peserta didik yang belajar hanya dengan melihat buku teks biasa (buku biasa) saja. Sementara itu, Ramdani, D. (2016) menyatakan bahwa penggunaan multimedia pembelajaran interaktif memberikan pengaruh yang signifikan terhadap hasil belajar kognitif dan kemampuan berfikir kreatif siswa.

Pelaksanaan pembelajaran merupakan hasil integrasi dari beberapa komponen yang memiliki fungsi tersendiri dengan maksud agar ketercapaian tujuan pembelajaran dapat 
terpenuhi. Menurut Rusman dkk. (2012: 41) ciri utama dalam kegiatan pembelajaran adalah adanya interaksi. Interaksi yang terjadi antara siswa dengan guru, teman-temannya, alat, media pembelajaran, dan/atau sumber-sumber belajar yang lain. Sedangkan ciri-ciri lainnya dari pembelajaran ini berkaitan dengan komponen-komponen pembelajaran itu sendiri. Dalam pembelajaran akan terdapat komponen-komponen sebagai berikut; tujuan, bahan/materi, strategi, media, dan evaluasi pembelajaran.

Tujuan penelitian ini adalah untuk memperoleh informasi tentang perbedaan hasil belajar siswa yang menggunakan multimedia interaktif dengan buku teks dalam pembelajaran biologi subkonsep sistem saraf di SMA.

\section{METODOLOGI PENELITIAN}

Jenis metode penelitian yang digunakan adalah quasi-eksperimental design dengan desain penelitian Control Group Pretest-Posttest Design yang digunakan untuk mengetahui pengaruh dari suatu perlakuan terhadap subjek penelitian.

Terdapat dua kelompok yang dipilih, kemudian diberi tes awal untuk mengetahui keadaan awal adakah perbedaan antara kelompok eksperimen dan kelompok kontrol. Hasil tes awal yang baik adalah bila nilai kelompok eksperimen tidak berbeda secara signifikan. Dalam hal ini dilihat perbedaan pencapaian antara kelompok eksperimen $\left(\mathrm{O}_{2}-\mathrm{O}_{1}\right)$ dengan pencapaian kelompok kontrol $\mathrm{O}_{4}-\mathrm{O}_{3}$ ) dalam Arikunto (2002: 80).

Penelitian ini dilakukan di SMAN 1 Ciawigebang, di Kota Kuningan. Pengambilan kriteria sekolah sebagai tempat penelitian dilakukan dengan cara sengaja dipilih. Penelitian ini dilaksanakan pada semester I tahun ajaran 2018-2019. Penelitian dilakukan sebanyak 2 kali pertemuan. Populasi penelitian adalah seluruh siswa kelas XI SMAN 1 Ciawigebang sebanyak 7 kelas. Sampel yang digunakan dalam penelitian sebanyak dua kelas yaitu kelas XI-MIPA I dan XI-MIPA II.

Instrumen yang digunakan dalam penelitian ini adalah tes objektif bentuk pilihan ganda dengan 30 soal. Soal tersebut diujicobakan dikelas XII yang telah mendapatkan materi subkonsep sistem saraf. Selanjutnya hasil uji coba soal dianalisis baik tingkat kesukarannya, daya pembeda, validitas maupun reliabilitas.

Tahap selanjutnya adalah melakukan tes pada kelas eksperimen dan kontrol. Data yang diperoleh kemudian dilakukan uji normalitas, homogenitas, dan selanjutnya uji t untuk mengetahui perbedaan rata-rata dari kedua kelas. 


\section{HASIL DAN PEMBAHASAN}

Kegiatan pembelajaran selama penelitian berlangsung menggunakan multimedia interaktif pada kelas eksperimen dan metode pembelajaran ceramah berbasis buku teks pada kelas kontrol. Untuk mengetahui adanya perbedaan hasil belajar siswa yang menggunakan multimedia interaktif dengan pembelajaran yang menggunakan buku teks dilakukan tes. Tes dilaksanakan sebelum pembelajaran (pretest) dan sesudah pembelajaran (postest) dengan soal pilihan ganda sebanyak 30 soal yang terdiri dari empat pilihan jawaban yaitu a, b, c, dan d yang telah dilakukan uji validitas, reliabilitas, daya pembeda dan tingkat kesukarannya. Dengan menggunakan soal yang sama disetiap kelas penelitian, maka dapat diketahui perbedaan hasil belajar siswa. Hasil belajar siswa tersebut kemudian diolah menjadi suatu data yang dibutuhkan untuk menjawab rumusan masalah apakah terdapat perbedaan hasil belajar siswa yang menggunakan multimedia interaktif dengan buku teks dalam pembelajaran biologi subkonsep sistem saraf di SMA.

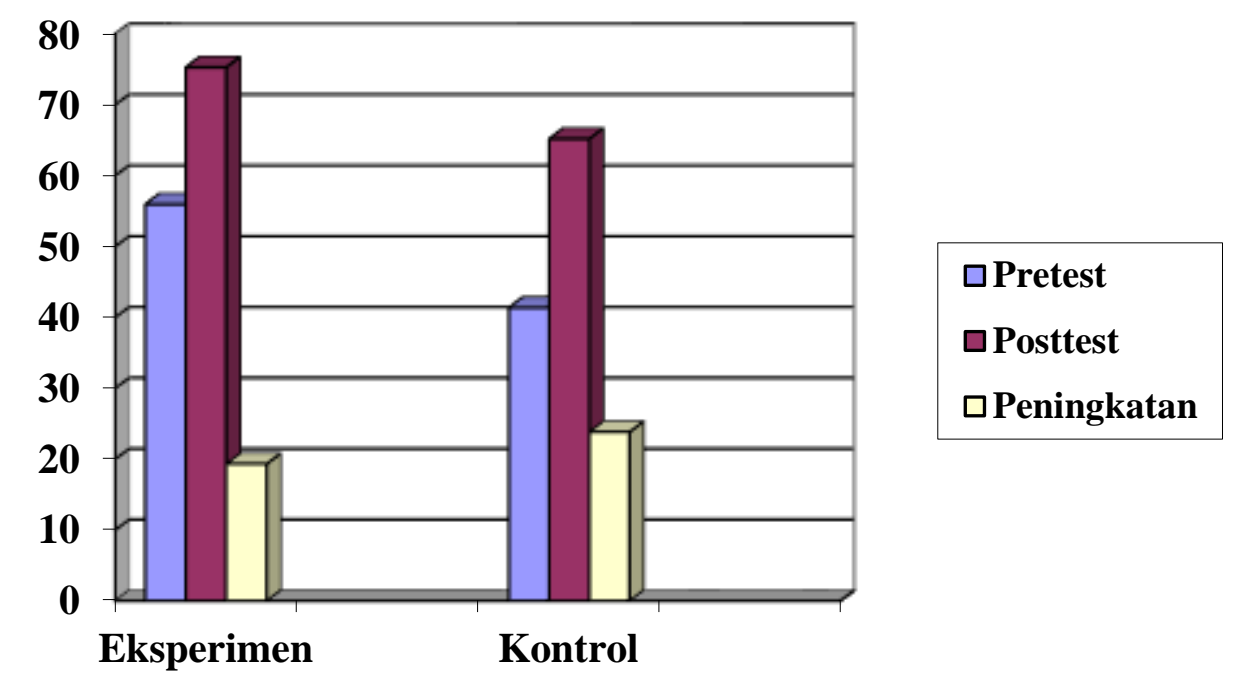

Gambar 1. Hasil Pretest dan Posttest Kelas Eksperimen dan Kontrol

Rata-rata pretest kelas eksperimen diperoleh angka sebesar 55.97 dan posttest 75.30, sedangkan rata-rata pretest kelas kontrol diperoleh angka sebesar 41.37 dan postest 65.20. Berdasarkan hasil tersebut, terdapat peningkatan hasil belajar siswa di kelas eksperimen sebesar 19.33 dan kelas kontrol sebesar 23.83. Hal tersebut menunjukkan bahwa terdapat perbedaan hasil belajar siswa antara kelas eksperimen dengan kelas kontrol.

Hasil uji normalitas menunjukkan bahwa harga Chi-Kuadrat masing-masing variable terletak dibawah penolakan yang ditentukan. Kesimpulan, bahwa keempat subjek penelitian berasal dari populasi yang berdistribusi normal. Berdasarkan uji homogenitas data pretest 
kelas eksperimen dan kontrol diperoleh $F_{\text {hitung }}=1,063$ dan $F_{0,025(29,29)}=1,85$ yang berarti bahwa data pretest eksperimen dan kontrol mempunyai varians yang homogen. Sementara itu, hasil posttest kelas eksperimen dan kontrol diperoleh $\mathrm{F}_{\text {hitung }}=1,172$ dan $\mathrm{F}_{0,025(29,29)}=$ 1,85 yang menunjukkan bahwa data posttest kelas eksperimen dan kontrol mempunyai varians yang homogen. Uji perbedaan dua rata-rata pretest kelas eksperimen dan kontrol diperoleh angka sebesar 55,97 untuk kelas eksperimen dan 41,37 untuk kelas kontrol. Pengujian hipotesis pada taraf signifikansi $\alpha=5 \%$ yaitu $-2,045 \leq 1,21 \leq 2,045$ yang artinya tidak terdapat perbedaan rata-rata pretest antara kelas eksperimen dan kelas kontrol. Selanjutnya, hasil posttest menunjukkan bahwa nilai rata-rata kelas eksperimen sebesar 75,30 dan kelas kontrol 65,20. Pengujian hipotesis pada taraf signifikansi $\alpha=5 \%$ diperoleh $t_{0,975(58)}=2,045$ dan $t_{\text {hitung }}=2,42$. Hasil tersebut menunjukkan bahwa a $t_{\text {hitung }}>t_{\text {tabel }}$ yaitu 2,42 $>$ 2,045 yang menunjukkan bahwa terdapat perbedaan rata-rata postest kelas eksperimen dan kelas kontrol, hasil tersebut memberikan gambaran bahwa hasil belajar siswa yang menggunakan multimedia interaktif dalam pembelajaran biologi subkonsep sistem saraf di SMA mengalami peningkatan yang lebih baik daripada pembelajaran dengan menggunakan buku teks.

Multimedia interaktif menurut Munir (2012: 110) merupakan perpaduan antara berbagai media (format file) yang berupa teks, gambar (vector atau bitmap), grafik, sound, animasi, video, interaksi, dan lain-lain yang telah dikemas menjadi file digital (komputerisasi), digunakan untuk menyampaikan pesan kepada publik. Dengan terdapatnya teks, gambar, grafik, sound (suara), animasi dan video multimedia mempunyai fungsi interaktif dalam pembelajaran. Fungsi interaktif tersebut karena multimedia melibatkan komunikasi dua arah atau lebih dari komponen-komponen komunikasi. Sementara itu Buku teks menurut Muslich (2010: 50) berisi uraian bahan tentang mata pelajaran atau bidang studi tertentu, yang disusun secara sistematis dan telah diseleksi berdasarkan tujuan tertentu, orientasi pembelajaran, dan perkembangan siswa untuk diasimilasikan.

Berdasarkan definisi tersebut, kompleksitas multimedia interaktif lebih baik dibandingkan dengan buku teks yang hanya memuat uraian bahan tentang mata pelajaran atau bidang studi tertentu saja. Munir (2012: 45) mengatakan bahwa setelah melakukan perbandingan, dikatakan bahwa peserta didik yang belajar dengan melihat gambar animasi ternyata lebih mudah mengerti materi yang disampaikan dibandingkan dengan peserta didik yang belajar hanya dengan melihat buku teks biasa (buku biasa) saja.

Pembelajaran multimedia interaktif menurut Saluky (2016) bertujuan untuk memudahkan proses pembelajaran dan menumbuhkan kekreatifan serta inovasi guru dalam 
mendesain proses pembelajaran. Menurut Pujawan (2012) penggunaan media pembelajaran interaktif mempunyai manfaat, antara lain pembelajar dapat belajar secara mandiri menurut tingkat kemampuannya atau dalam kelompok kecil, lebih efektif untuk menjelaskan materi sehingga siswa mendapatkan pengalaman belajar yang menarik, dan lain-lain. Kehadiran media pembelajaran interaktif dalam proses pembelajaran membuat suasana pembelajaran yang berbeda, karena materi yang dulunya diajarkan dengan metode ceramah yang monoton dapat divariasikan dengan tayangan yang memuat teks, suara, gambar bergerak, dan video (Putri \& Sibeua, 2014).

Penggunaan multimedia interaktif dalam pembelajaran biologi subkonsep sistem saraf di SMA pada kenyataannya mampu meningkatkan hasil belajar siswa. Hal tersebut disebabkan oleh penggunaan multimedia interaktif yang memberikan suasana belajar yang baru, menarik, dan menyenangkan bagi siswa. Interaksi yang terjadi antara siswa dengan multimedia dalam pembelajaran memberikan pengalaman belajar yang baru bagi siswa dibandingkan dengan pembelajaran konvensional yang hanya menjadikan siswa pasif dalam proses pembelajaran. Pembelajaran konvensinal dengan metode ceramah berbasis buku teks dianggap sebagai suatu proses pembelajaran yang membosankan bagi siswa, karena proses pembelajaran yang terjadi hanya bersifat satu arah sehingga menyebabkan hasil belajar siswa kurang maksimal. Hal tersebut dibuktikan dengan hasil penelitian yang telah dilakukan bahwa kelas eksperimen memperoleh rata-rata hasil belajar yang lebih baik dibandingkan dengan kelas kontrol.

Penelitian relevan yang telah dilakukan oleh Parata, T.P. (2018) yang menyatakan bahwa multimedia interaktif sebagai media pembelajaran berpengaruh terhadap hasil belajar kognitif siswa. Hal senada dikatakan oleh Triyanti, M. (2015) yang menyatakan bahwa terjadi peningkatan hasil belajar siswa setelah menggunakan multimedia interaktif. Sejalan dengan itu, penelitian Dalero, M.D. (2013) yang menyatakan bahwa pemanfaatan Multimedia Interaktif dapat meningkatkan hasil belajar siswa. Sementara itu, Ratini (2011) menyatakan bahwa pembelajaran biologi menggunakan multimedia interaktif dapat meningkatkan aktivitas dan hasil belajar siswa. Senada dengan itu, Wulandari (2017) menyatakan bahwa penggunaan multimedia interaktif berbasis macromedia flash 8 berpengaruh terhadap keaktifan siswa dan hasil belajar Biologi pada materi sistem saraf siswa kelas XI SMA PPMI Assalaam Sukoharjo Tahun Pelajaran 2016/2017. 


\section{SIMPULAN}

Berdasarkan penelitian tersebut dapat disimpulkan bahwa terdapat perbedaan hasil belajar siswa yang menggunakan multimedia interaktif dengan buku teks pada subkonsep sistem saraf di SMA. Selain daripada itu, pembelajaran multimedia interaktif juga mampu meningkatkan hasil belajar siswa, hasil tersebut dibuktikan dengan rata-rata perolehan nilai hasil belajar siswa yang menggunakan multimedia interaktif memperoleh hasil yang lebih baik daripada siswa yang belajar dengan menggunakan buku teks. Pembelajaran dengan menggunakan multimedia interaktif dengan buku teks akan berjalan dengan baik apabila guru memanfaatkan sumber belajar tersebut sesuai dengan kebutuhan materi pembelajaran.

\section{DAFTAR PUSTAKA}

Arikunto, S. (2002). Prosedur Penelitian. Jakarta: PT. Rineka Cipta.

Dalero, Mega Dayatri Palapa, \& Tommy M. Pendong, D.F. (2013). Pemanfaatan Multimedia Interaktif dalam Meningkatkan Hasil Belajar Siswa Biologi pada Materi Sistem Pencernaan Kelas XI IPA SMA Katolik Don Bosco Bitung. JSME MIPA UNIMA. 1(4).

Munir. (2012). Multimedia. Bandung: Alfabeta.

Musfiqon. (2012). Pengembangan Media dan Sumber Pembelajaran. Jakarta: PT. Prestasi Pustakaraya.

Muslich, Masnur. (2010). Textbook Writing: Dasar-dasar Pemahaman, Penulisan, dan Pemakaian Buku Teks. Jogjakarta: Ar-Ruzz Media.

Parata, T.P., \& Zawawi, M. (2018). Pemanfaatan Multimedia Interaktif Pembelajaran IPABiologi Terhadap Motivasi dan Kemampuan Kognitif Siswa SMP Negeri 14 Kota Palembang. Jurnal Ecoment Global. 3(2).

Pujawan, K. A. H. (2012). Pengembangan Multimedia Interaktif Pembelajaran Animasi Berbasis Inkuiri untuk Siswa Kelas XI Multimedia SMK TI Bali Global Singaraja. Jurnal Teknologi Pembelajaran Indonesia. 1(1).

Putri, I. P., \& Sibuea, A. M. (2014). Pengembangan Media Pembelajaran Interaktif Pada Mata Pelajaran Fisika. Jurnal Teknologi Informasi dan Komunikasi dalam Pendidikan, 1(2), (2014).

Ramdani, D. (2016). Pengaruh Multimedia Pembelajaran Interaktif (MPI) Terhadap Hasil Belajar Kognitif Peserta Didik. Bioedusiana, 1(1).

Ratini. (2011). Penggunaan Multimedia Interaktif Untuk Meningkatkan Aktivitas dan Hasil Belajar Biologi Pada Siswa SMA Muhammadiyah 1 Metro Tahun Pelajaran 2010/2011. Bio Edukasi Jurnal Pendidikan Biologi, 2(1). 
Rusman, dkk. (2011). Pembelajaran Berbasis Teknologi Informasi dan Komunikasi. Jakarta: PT. Rajagrafindo Persada.

Saluky. (2016). Pengembangan Bahan Ajar Matematika Berbasis WEB dengan Menggunakan WordPress. Jurnal EduMa, 5(1).

Triyanti, M. (2015). Pengembangan Multimedia Interaktif pada Materi Sistem Saraf untuk Meningkatkan Motivasi dan Hasil Belajar Siswa SMA Kelas XI. Jurnal Bioedukatika, $3(2)$.

Wulandari, E. (2017). Penerapan Multimedia Interaktif Berbasis Macromedia Flash 8 Terhadap Keaktifan dan Hasil Belajar Biologi Materi Sistem Saraf Manusia Pada Siswa Kelas XI SMA PPMI Assalaam Sukoharjo Tahun Pelajaran 2016/2017. Skripsi. Surakarta: Program Studi Pendidikan Biologi Fakultas Keguruan dan Ilmu Pendidikan Universitas Muhammadiyah Surakarta. 